Bài báo khoa học

\title{
Mô phỏng sự phụ thuộc xâm nhập mặn và các yếu tố thủy văn bằng MIKE 3 - Trường hợp cửa sông Vệ, Quảng Ngãi
}

\author{
Bùi Tá Long ${ }^{1 *}$, Lê Thị Mỹ Diệp ${ }^{2}$ \\ ${ }^{1}$ Trường Đại học Bách Khoa Tp. HCM; longbt62@hcmut.edu.vn \\ ${ }^{2}$ Viện Khoa học và Thủy lợi Miền Nam; diepmoitruongmdquangngai@gmail.com \\ * Tác giả liên hệ: longbt62@hcmut.edu.vn; Tel.: +84-918017376
}

Ban Biên tập nhận bài: 09/03/2021; Ngày phản biện xong: 6/4/2021; Ngày đăng bài: $25 / 5 / 2021$

Tóm tắt: Trong nhiều năm qua, vấn đề xâm nhập mặn được quan tâm bởi ảnh hưởng tiêu cực của nó tới phát triển kinh tế-xã hội, đặc biệt tại vùng Đồng Bằng Sông Cửu Long. Nhiều chương trình, đề tài nghiên cứu cho khu vực này, trong đó đa số các nghiên cứu được thực hiện ứng dụng mô hình MIKE 11 để tính toán mô phỏng. Các kết quả nhận được tập trung làm rõ phạm vi mặn được truyền vào, chưa quan tâm nhiều tới cơ chế truyền mặn (theo bề mặt hay đáy). Sự phụ thuộc phạm vi truyền mặn vào các yếu tố dòng chảy, chế độ triều chưa được quan tâm đúng mức. Bên cạnh đó, số lượng nghiên cứu về xâm nhập mặn tại miền Trung khá khiêm tốn dẫn tới nhiều vấn đề khoa học, thực tiễn tuy được đặt ra nhưng chưa tìm ra câu trả lời. Nghiên cứu này, mô hình MIKE 3 được sử dụng hướng tới làm rõ cơ chế mặn được từ biển vào sông, cũng như sự phụ thuộc phạm vi truyền mặn vào các yếu tố dòng chảy (sông), chế độ triều (biển) - chọn sông Vệ, Quảng Ngãi làm khu vực nghiên cứu. Kết quả mô phỏng được kiểm định dựa trên chuỗi số liệu thực đo liên tục trong 48 tiếng, đã cho kêt quả mức tốt và rất tốt tại mặt cắt $\mathrm{MC} 0$ với $\mathrm{R}^{2}$ đạt 0,825 , Nash đạt 0,798 , PBIAS đạt 6,919 , RSR đạt 0,524 . Mô hình MIKE 3 sau bước kiểm định, được áp dụng mô phỏng sự phụ thuộc mức độ, phạm vi mặn phụ thuộc vào chế độ thủy triều, lưu lượng dòng chảy. Mô hình 3 chiều cho phép làm sáng tỏ sự khác biệt về truyền mặn giữa mùa khô và mùa mưa tại sông Vệ, đặc biệt là cơ chế truyền mặn tại mặt cắt $\mathrm{MC} 0$, ngay vùng cửa sông.

Từ khóa: Mưa-dòng chảy; SWAT; NAM; MIKE 3; sông Vệ.

\section{Mở đầu}

Xâm nhập mặn là hiện tượng thủy văn tự nhiên ở các vùng ven biển khi nước mặn xâm nhập vào kênh sông và hòa trộn với nước ngọt. Đây là một trong những quá trình chính dẫn tới suy giảm cả chất lượng nước mặt và nước ngầm, làm cho nước không đạt mục tiêu sử dụng của con người [1]. Xâm nhập mặn làm tăng áp lực cho hệ thống cấp nước sinh hoạt ở các vùng dân cư ven biển nơi có khoảng $80 \%$ các thành phố lớn nhất trên thế giới [2-4]. Xâm nhập mặn cũng có thể làm thay đổi đa dạng sinh học và các quần xã thủy sinh do mất môi trường sống thích hợp cho chúng [5-7]. Xâm nhập mặn tác động sâu sắc đến nguồn nước ngọt, sinh kế của dân cư và sự phát triển xung quanh [8]. Hơn nữa, nước mặn có thể tạo điều kiện thuận lợi cho quá trình sụt lún của các trầm tích mịn, kích thích tích cực sự hình thành vành đai đục gần các cửa sông nơi ô nhiễm thứ cấp xảy ra [9]. Chính vì vậy, xâm nhập mặn luôn là đối tượng nghiên cứu của nhiều tác giả ngoài nước [1-7], cũng như trong nước [11-19]. Dù đã có nhiều nghiên cứu về xâm nhập mặn nhưng vẫn còn những kiến thức cơ chế xâm nhập mặn cho đối tượng cụ thể vẫn cần được làm rõ [2]. 
Việt Nam hiện có 28 tỉnh, thành có biển với 125 huyện ven biển, trải dọc theo bờ biển dài hơn 3.260 km, từ Quảng Ninh đến Kiên Giang, trong đó có tỉnh Quảng Ngãi. Trong nhiều năm qua, xâm nhập mặn là một vấn đề môi trường lớn ở nhiều vùng của đất nước, đặc biệt là ở các cửa sông vì nó làm xáo trộn nguồn cung cấp nước dân cư, nông nghiệp, công nghiệp và đe dọa sự ổn định của các hệ sinh thái cửa sông [10]. Trong nhiều năm qua, xâm nhập mặn luôn là đối tượng nghiên cứu của nhiều nhóm các tác giả [11-17]. Các nghiên cứu khác đều sử dụng mô hình toán 1D [14-19], 2D [20]. Hạn chế của các nghiên cứu này là chưa làm rõ cơ chế mặn truyền từ biển và sông theo bề mặt hay theo đáy. Từ đó nghiên cứu này đã áp dụng mô hình diễn toán MIKE 3 để mô phỏng dòng chạy, quá trình truyền mặn ở khu vực cửa sông khu vực nghiên cứu.

Trong nghiên cứu, mô hình 3D được áp dụng để mô phỏng truyền mặn từ biển vào sông nhằm làm rõ làm rõ cơ chế truyền mặn từ biển vào sông. Nghiên cứu cũng hướng tới làm rõ sự phụ thuộc truyền mặn vào chế độ triều từ phía biển và lưu lượng dòng chảy từ phía sông. Các module MIKE $3 \mathrm{HD}, \mathrm{AD}$ được hiệu chỉnh, kiểm định trước khi được sử dụng để mô phỏng truyền mặn. Các tiêu chí đánh giá NSE, PBIAS và RSR được sử dụng để làm rõ độ chính xác kết quả mô phỏng

\section{Phương pháp và số liệu}

\subsection{Khu vục nghiên cứu}

Sông Vệ là sông lớn thứ hai nằm trong bốn hệ thống sông lớn nhất thuộc tỉnh Quảng Ngãi, có diện tích $1263 \mathrm{~km}^{2}$, chiếm 24,51\% diện tích tự nhiên của tỉnh Quảng Ngãi [21]. Lưu vực sông Vệ bao gồm: toàn bộ huyện Mộ Đức; một phần lớn huyện Ba Tơ, huyện Nghĩa Hành; một phần nhỏ huyện Đức Phổ và huyện Tư Nghĩa của tỉnh Quảng Ngãi. Ranh giới lưu vực sông Vệ gồm: Phía Bắc giáp lưu vực sông Trà Khúc tỉnh Quảng Ngãi; Phía Nam giáp lưu vực sông Trà Câu tỉnh Quảng Ngãi; Phía Tây giáp lưu vực sông Trà Khúc, Sê San; Phía Đông giáp với biển Đông.

Xâm nhập mặn tại vùng hạ du sông Vệ, Quảng Ngãi là đối tượng của một số nghiên cứu gần đây [19-21]. Nghiên cứu [19] tập trung vào xâm nhập mặn sông Trà Khúc-sông Vệ, Trong nghiên cứu này sử dụng mô hình thủy động lực học $1 \mathrm{D}$ kết hợp với mô hình truyền tải khuếch tán để đánh giá tình hình xâm nhập mặn ở hạ lưu sông Trà Khúc-sông Vệ thuộc tỉnh Quảng Ngãi, dự báo xâm nhập mặn do ảnh hưởng của biến đổi khí hậu và nước biển dâng. Mô hình được xây dựng dựa trên cơ sở dữ liệu năm 2002 và 2013, đưa ra đánh giá mức độ xâm nhập mặn cũng như dự báo dự báo xâm nhập mặn cho các năm 2020 và 2030 . Tuy nhiên, nghiên cứu này chỉ tập trung vào sông Trà Khúc, không đề cập tới sông Vệ.

Trong nghiên cứu [21], nhóm tác giả bài báo này đã sử dụng SWAT/NAM/MIKE xây dựng bộ thông số thủy văn và thủy lực phục vụ cho tính toán dòng chảy - trường hợp sông Vệ, Quảng Ngãi. Đã xác định được bộ thông số thủy văn cho khu vực hạ lưu lưu vực sông Vệ, gồm: $U_{\max }$ là lượng nước tối đa trong bể chứa mặt $(\mathrm{mm}) ; \mathrm{L}_{\max }$ là lượng ẩm lớn nhất trong bể chứa tầng rễ cây (mm); CQOF là hệ số dòng chảy mặt, không thứ nguyên, phản ánh điều kiện thấm; TOF là ngưỡng dưới của dòng chảy tràn; TIF là ngưỡng dưới của dòng chảy sát mặt; TG là giá trị ngưỡng tầng rễ cây; CKIF là hệ số thời gian dòng chảy sát mặt; CK12 là hằng số thời gian chảy truyền của dòng chảy mặt; $\mathrm{CKBF}$ là hằng số thời gian chảy truyền của dòng chảy ngầm. Trong nghiên cứu độc lập khác [21] đã nhận được bộ thông số thủy văn cho lưu vực sông Trà Khúc-Sông Vệ, kết quả so sánh giữa 2 bộ thông số trong [21] cho sai số không đáng kể. Nghiên cứu [20] sử dụng MIKE 21 đánh giá phạm vi và mức độ truyền mặn vùng cửa sông Vệ. 


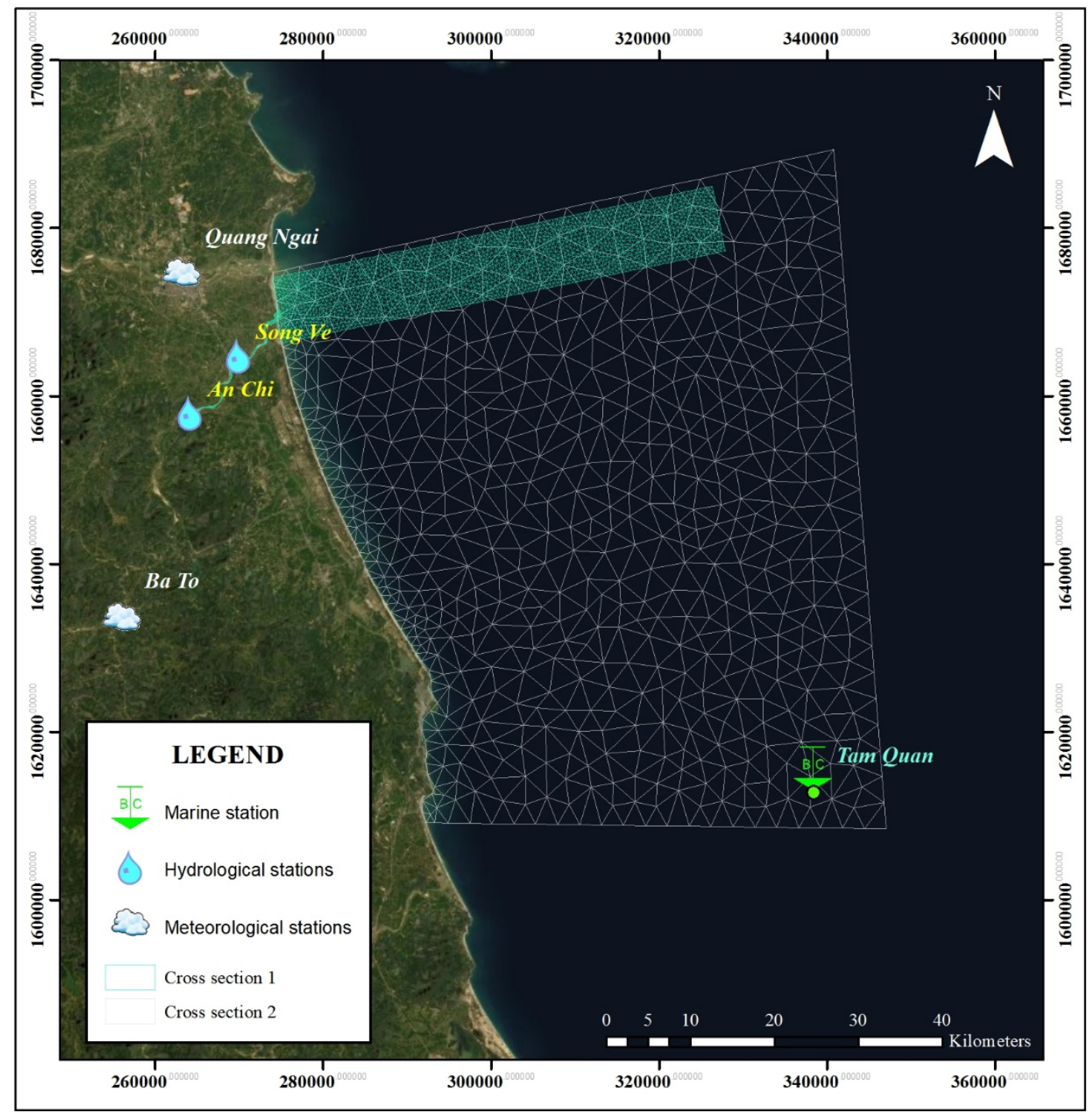

Hình 1. Vị trí, giới hạn khu vực nghiên cứu với lước D1 (nhỏ), D2 (lớn), 2 trạm đo thủy văn, 2 trạm đo khí tượng được sử dụng.

\subsection{Mô hình MIKE 3}

Bộ phần mềm MIKE là sản phẩm của Viện thủy lực Đan Mạch (DHI Water \& Environment), với các module như MIKE 11, MIKE 21, MIKE3 HD, AD, ST, MT, SW ... được sử dụng để mô phỏng các quá trình thủy động lực học hai chiều, ba chiều, sự vận chuyển và khuếch tán của các chất hòa tan và lơ lửng, bùn cát; sự lan truyền của sóng biển, tính toán sa bồi ở vùng cửa sông và ven biển. Nghiên cứu ứng dụng MIKE mô phỏng truyền mặn được thực hiện trong nhiều nghiên cứu trong nước [12-17, 22]; cũng như tại nước ngoài [23-25]. Phần dưới đây trình bày những module chính, gồm MIKE $3 \mathrm{HD}, \mathrm{AD}$ được sử dụng trong nghiên cứu này, tham khảo từ [26-28].

\subsubsection{MIKE 3 HD}

Module MIKE 3 HD được xây dựng trên hệ phương trình Navier-Stokes trung bình Reynolds cho chất lỏng không nén được 2 hoặc 3 chiều kết hợp với giả thiết Boussinesq và giả 
thiết áp suất thuỷ tĩnh, gồm: phương trình liên tục, động lượng, được khép kín bởi sơ đồ khép kín rối. Với trường hợp ba chiều thì sử dụng xấp xỉ chuyển đồi hệ tọa độ sigma.

Phương trình liên tục:

$$
\frac{\partial u}{\partial x}+\frac{\partial v}{\partial y}+\frac{\partial w}{\partial z}=S
$$

Phương trình động lượng theo phương $\mathrm{x}$ và $\mathrm{y}$ tương ứng:

$$
\begin{gathered}
\frac{\partial u}{\partial t}+\frac{\partial u^{2}}{\partial x}+\frac{\partial v u}{\partial y}+\frac{\partial w u}{\partial z}=f v-g \frac{\partial \eta}{\partial x}-\frac{1}{\rho_{0}} \frac{\partial p_{a}}{\partial x}-\frac{g}{\rho_{0}} \int_{z}^{\eta} \frac{\partial \rho}{\partial x}+F_{u}+\frac{\partial}{\partial z}\left(v_{t} \frac{\partial u}{\partial z}\right)+u_{s} S \\
\frac{\partial v}{\partial t}+\frac{\partial v^{2}}{\partial y}+\frac{\partial u v}{\partial x}+\frac{\partial w v}{\partial z}=f u-g \frac{\partial \eta}{\partial y}-\frac{1}{\rho_{0}} \frac{\partial p_{a}}{\partial y}-\frac{g}{\rho_{0}} \int_{z}^{\eta} \frac{\partial \rho}{\partial y}+F_{v}+\frac{\partial}{\partial z}\left(v_{t} \frac{\partial v}{\partial z}\right)+v_{s} S \\
F_{u}=\frac{\partial}{\partial x}\left(2 A \frac{\partial u}{\partial x}\right)+\frac{\partial}{\partial y}\left(2 A\left(\frac{\partial u}{\partial y}+\frac{\partial v}{\partial x}\right)\right) \\
F_{v}=\frac{\partial}{\partial y}\left(2 A \frac{\partial v}{\partial y}\right)+\frac{\partial}{\partial x}\left(2 A\left(\frac{\partial u}{\partial y}+\frac{\partial v}{\partial x}\right)\right)
\end{gathered}
$$

Trong các phương trình (1)-(5): $\mathrm{t}$ là thời gian; $\mathrm{x}, \mathrm{y}$ và $\mathrm{z}$ là toạ độ Đề các; $\eta$ là dao động mực nước $; \mathrm{u}(\mathrm{x}, \mathrm{y}, \mathrm{z}, \mathrm{t}), \mathrm{v}(\mathrm{x}, \mathrm{y}, \mathrm{z}, \mathrm{t}), \mathrm{w}(\mathrm{x}, \mathrm{y}, \mathrm{z}, \mathrm{t})$ là 3 thành phần vec tơ dòng chảy, $\mathrm{d}$ là độ sâu; $\mathrm{h}=\eta+\mathrm{d}$ là độ sâu tổng cộng; $\mathrm{u}, \mathrm{v}$ và $\mathrm{w}$ là thành phần vận tốc theo phương $\mathrm{x}, \mathrm{y}$ và $\mathrm{z} ; \mathrm{f}=2 \Omega \sin \Phi$ là tham số Coriolis; $g$ là gia tốc trọng trường; $\rho$ là mật độ nước; $v_{t}$ là nhớt rối thẳng đứng; $\mathrm{p}_{\mathrm{a}}$ là áp suất khí quyển; $\rho_{0}$ là mật độ chuẩn; $\mathrm{S}$ là lưu lượng do các nguồn điểm; $\left(\mathrm{u}_{\mathrm{s}}, \mathrm{v}_{\mathrm{s}}\right)$ là vận tốc của dòng lưu lượng đi vào miền tính; $\mathrm{F}_{\mathrm{u}}, \mathrm{F}_{\mathrm{v}}$ là các số hạng ứng suất theo phương ngang; $\mathrm{A}$ là độ rối nhớt theo phương ngang. Bộ công cụ MIKE 3 HD cho phép hiệu chỉnh 2 tham số chính là độ rối nhớt (eddy viscosity coefficient, $\mathrm{v}, \mathrm{m}^{2} / \mathrm{s}$ ) và chiều cao độ nhám (roughness height, $\mathrm{k}_{\mathrm{s}}$, m) [30].

\subsubsection{MIKE $3 \mathrm{AD}$}

Module tải-khuếch tán (Advection Dispersion - AD) trong MIKE 3 giải phương trình tảikhuếch tán cho chất bảo toàn hay hòa tan. Phương trình truyền mặn được xây dựng dựa trên định luật bảo toàn khối lượng lưu ý tới lượng chất đi vào-ra trong một khối thể tích. Phương trình lan truyền cho mặn có dạng [28]:

$$
\frac{\partial s}{\partial t}+\frac{\partial u s}{\partial x}+\frac{\partial v s}{\partial y}+\frac{\partial w s}{\partial z}=\frac{\partial}{\partial x}\left(D_{h} \frac{\partial s}{\partial x}\right)+\frac{\partial}{\partial z}\left(D_{h} \frac{\partial s}{\partial y}\right)+\frac{\partial}{\partial z}\left(D_{v} \frac{\partial s}{\partial z}\right)+s_{s} S
$$

Trong phương trình $(6) \mathrm{D}_{\mathrm{v}}$ là hệ số khuếch tán rối thẳng đứng; $\mathrm{D}_{\mathrm{h}}$ là hệ số khuếch tán rối theo phương ngang; $\mathrm{S}$ là số hạng nguồn; $\mathrm{S}_{\mathrm{s}}$ là độ mặn của nguồn.

\subsection{Dĩ liệu}

\subsection{1. Địa hình}

Dữ liệu DEM được lấy từ trang web http://gdex.cr.usgs.gov/gdex/ và sử dụng phần mềm SWAT phân chia khu vực nghiên cứu thành các lưu vực, sử dụng ArcGIS số hóa đoạn sông. Kết quả phân chia lưu vực là các file tiểu lưu vực được lưu dưới dạng shapefile [21]. Dữ liệu bản đồ và thuộc tính được sử dụng trong nghiên cứu này này gồm: bản đồ số hóa độ cao (DEM) lưu vực sông Vệ, bản đồ thổ nhưỡng, bản đồ sử dụng đất, bản đồ thảm phủ thực vật ứng với hiện trạng rừng, bản đồ mạng lưới sông suối và lưới trạm đo khí tượng thủy văn.

Dữ liệu địa hình chạy MIKE 3 trong nghiên cứu này được chia ra làm 2 nhóm. Nhóm thứ nhất liên quan tới vùng ven biển được thu thập, xử lý và chuyển vào phần mềm MIKE 3 [29], 
nhóm thứ hai liên quan tới đất liền và cửa sông gồm: số liệu thực đo 19 mặt cắt thực đo được kế thừa từ công trình [21]. Đoạn sông Vệ được xem xét trong nghiên cứu này được giới hạn từ thượng nguồn sông đến cửa Lở dài 21.47 km (Hình 2).

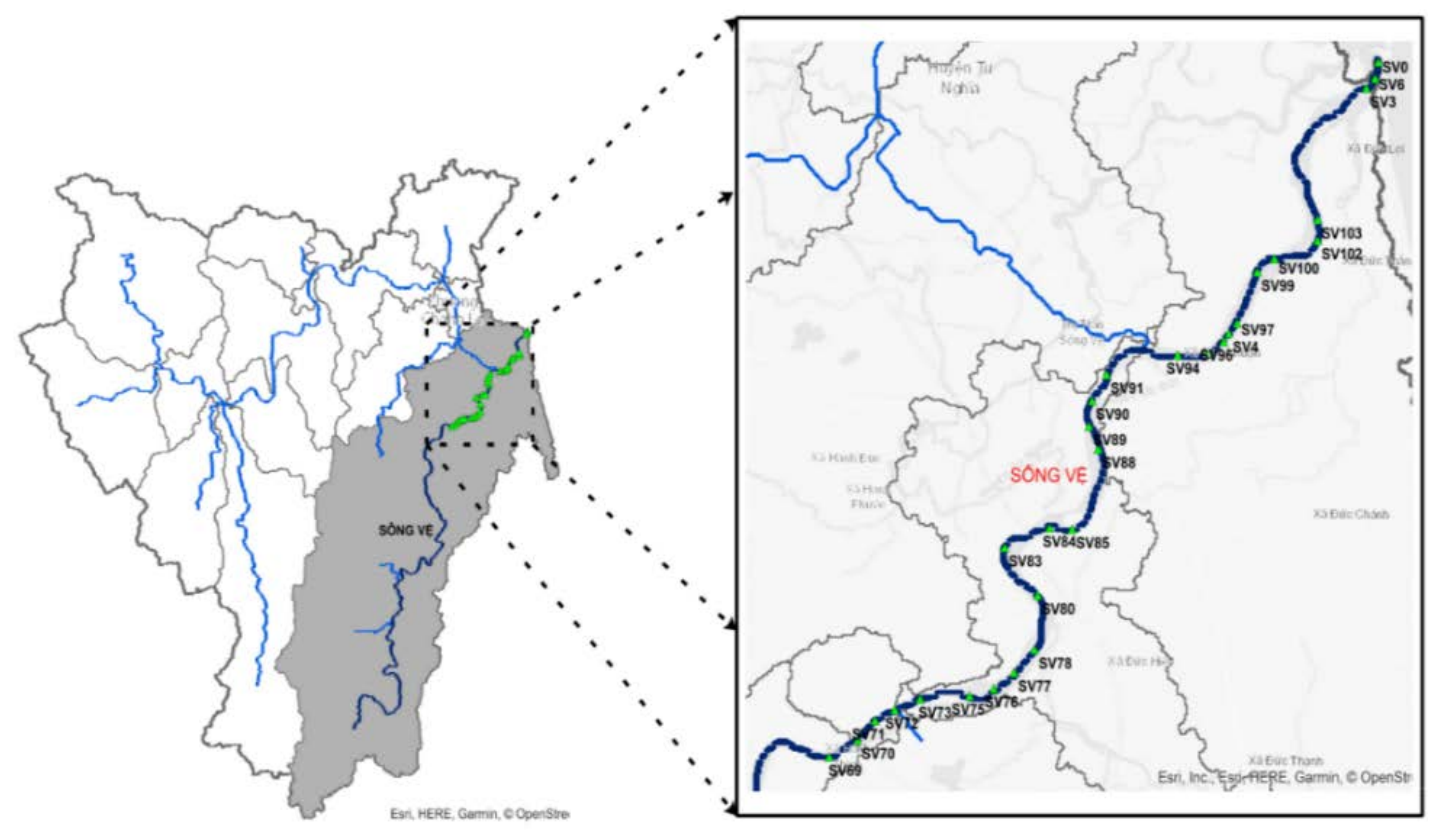

Hình 2. Địa hình vùng cửa sông và các vị trí đo mặt cắt sông Vệ.

\subsubsection{Yếu tố triều}

Sông Vệ chịu ảnh hưởng của biển Đông chế độ bán nhật triều với 4 thành phần thủy triều chính: M2, S2, N2, K2 được sử dụng để tính toán mô phỏng thủy lực [30]. Bộ thông số này đóng vai trò quan trọng trong module MIKE $3 \mathrm{HD}$ và $\mathrm{AD}$. Nghiên cứu này đã kế thừa kết quả nghiên cứu kiểm định từ đề tài cấp nhà nước theo số liệu thực đo liên tục 24/24 các thông số lưu lượng, mực nước tại 3 vị trí MC0, MC3, MC4 cho năm 2018 (Hình 1).

Bảng 1. Bảng sóng điều hòa lưu ý tới thủy triều [30].

\begin{tabular}{cccc}
\hline STT & Tên sóng & Ký hiệu & Chu kỳ \\
\hline 1 & Mặt trăng chính & M2 & 20 giờ \\
2 & Mặt trời chính & S2 & 10 giờ \\
3 & Mặt trăng chính & $\mathrm{O} 1$ & 30 giờ \\
4 & Mặt trăng mặt trời & K1 & 30 giờ \\
\hline
\end{tabular}

\subsubsection{Số liệu khí tượng}

Để chạy mô hình MIKE 3, số liệu về gió cho khu vực biển: miền D2, miền D1 được trích xuất từ mô hình $\mathrm{WRF}$ - sau khi bước hiệu chỉnh và kiểm định. Kết quả này được thể hiện trên Hình 3 cho thời điểm tháng 7/2018, Hình 4 cho thời điểm tháng 12/2018. Nghiên cứu [21] cho thấy vào tháng $7 / 2018$, lưu lượng trung bình ngày dòng chảy là bé nhất, còn tháng $12 / 2018$ có lưu lượng trung bình ngày lớn nhất. Module MIKE 3 chạy cho vùng biển yêu cầu số liệu gió theo giờ gồm vận tốc và hướng gió. Trong nghiên cứu này, đã sử dụng mô hình WRF để trích xuất theo giờ, điều mà các trạm quan trắc hiện có không thể đám ứng được. Đã thực hiện kiểm định mô hình cho cả 2 trường hợp, lưu ý và không lưu ý tới gió, và kết quả gió là yếu tố quan trọng trong nghiên cứu này. 


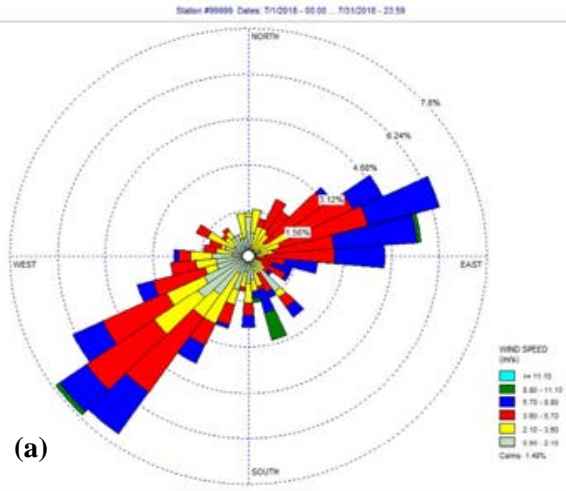

(a)

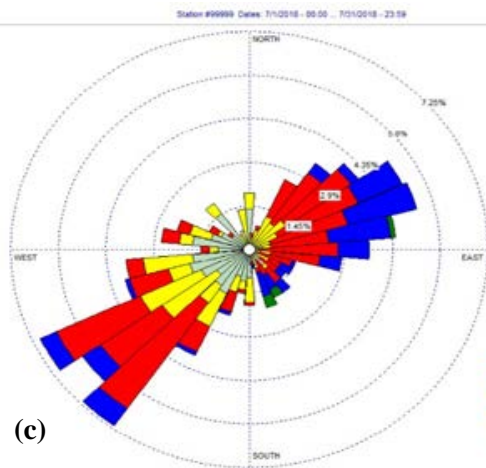

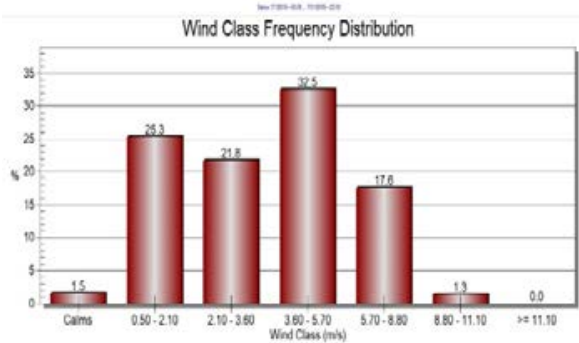

(b)

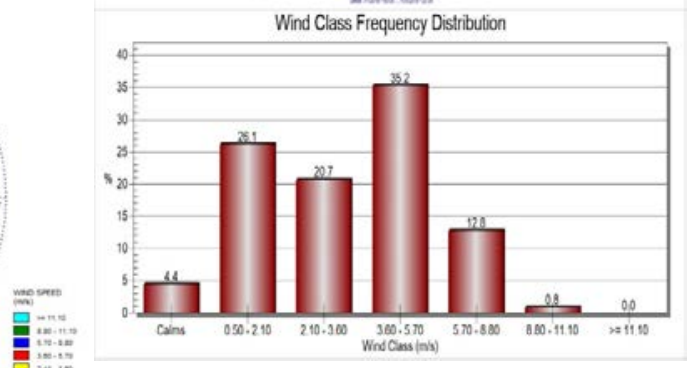

(d)

Hình 3. Dữ liệu khí tượng trong khu vực được sử dụng trong tính toán mô phỏng: (a) Hoa gió cho tháng 7/2018, khu vực biển; (b) Biểu đồ gió-vận tốc, tần suất tháng 7/2018, khu vực biển; (c) Hoa gió cho tháng 7/2018, khu vực sông; (d) Biểu đồ gió-vận tốc, tần suất tháng 7/2018, khu vực sông.

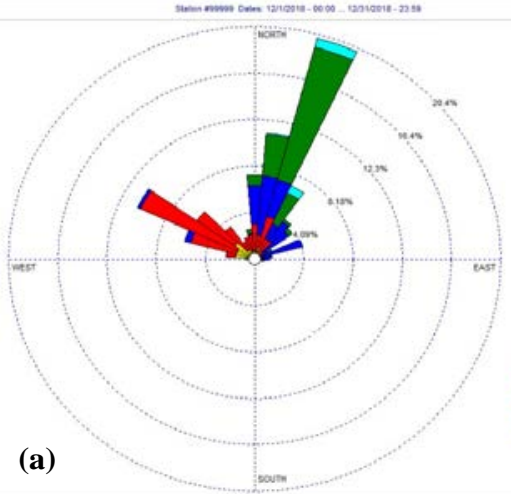

(a)

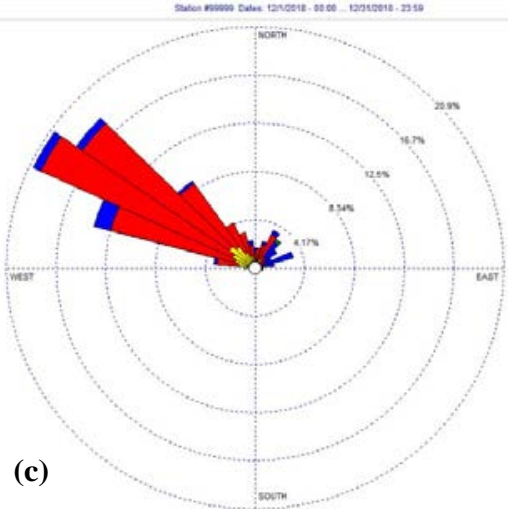

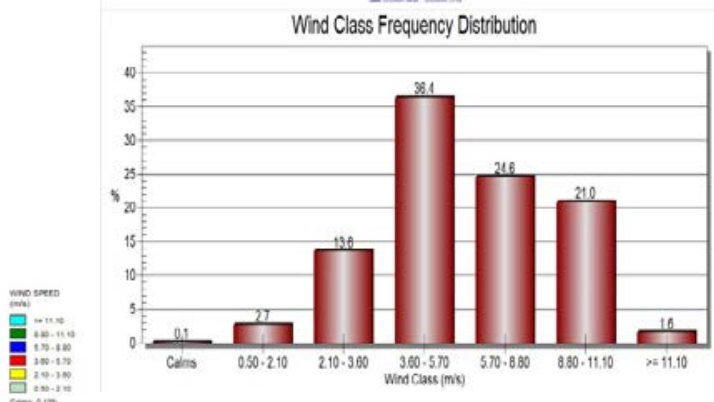

(b)

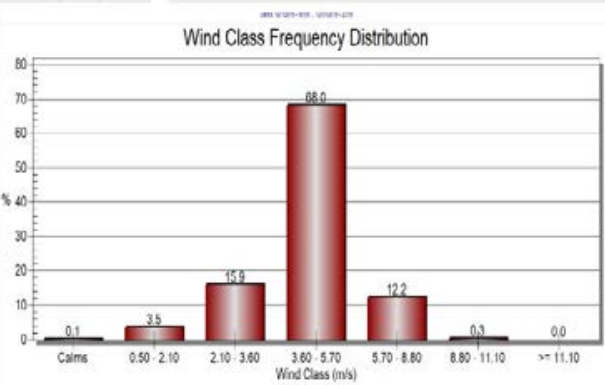

(d)

Hình 4. Dữ liệu khí tượng trong khu vực được sử dụng trong tính toán mô phỏng: (a) Hoa gió cho tháng 12/2018, khu vực biển; (b) Biểu đồ gió-vận tốc, tần suất tháng 12/2018, khu vực biển; (c) Hoa gió cho tháng 12/2018, khu vực sông; (d) Biểu đồ gió-vận tốc, tần suất tháng 12/2018, khu vực sông. 


\subsubsection{Số liệu mặn}

Để có số liệu cho bài báo này, đã thực hiện đo đạc thực địa với các thiết bị: máy đo lưu lượng nước tự động ADCP (Mỹ); máy thuỷ chuẩn NA2 Leica, LEICA (TC805), máy đo sâu hồi âm HONDEX PS-7 (Nhật); máy đo độ mặn; mia địa hình; máy GPS cầm tay; la bàn. Các yếu tố thủy văn được ghi nhận từ $0 \mathrm{~h}$ ngày 7-10 đến $23 \mathrm{~h}$ ngày 8-10-2018 và đo mặt cắt ngang và dẫn nối độ cao từ ngày 9-10 đến 10-10-2018. Đồng thời với việc đo mực nước, yếu tố độ mặn cũng được lấy mẫu và đo theo chế độ $24 / 24$ từ $0 \mathrm{~h}$ ngày 7-10 đến $23 \mathrm{~h}$ ngày 8-10-2018 tại cả 3 mặt cắt: mặt cắt 0 , mặt cắt 3 và mặt cắt 4 [20]. Đo lưu lượng nước bằng máy đo tự động $\operatorname{ADCP}($ Mỹ) được thực hiện tại 3 mặt cắt theo chế độ $24 / 24$ từ 0 h ngày $7-10$ đến 23 h ngày $8-$ 10-2018 (đồng thời với đo mực nước và đo mặn). Trên Hình 1 thể hiện miền tính toán gồm lước $\mathrm{D} 1$ gồm phần biển và phần sông Vệ, biên mặn phía biển được lấy bằng hằng số $32,5 \%$ [32-33], biên mặn $\mathrm{AD}$ trên thượng nguồn lấy bằng hằng số $0,05 \%$.

\subsection{Chỉ tiêu đánh giá}

Chỉ số đánh giá mức độ tương quan giữa kết quả tính toán và kết quả đo đạc, được xác định theo các công thức sau:

$$
\begin{gathered}
\text { NSE }=\frac{\sum_{\mathrm{i}=1}^{\mathrm{n}}\left(\mathrm{Q}_{\mathrm{i}}^{\text {sim }}-\mathrm{Q}_{\mathrm{i}}^{\text {obs }}\right)^{2}}{\sum_{\mathrm{i}=1}^{\mathrm{n}}\left(\mathrm{Q}_{\mathrm{i}}^{\text {obs }}-\overline{\mathrm{Q}}\right)^{2}}, \text { PBIAS }=\frac{\sum_{\mathrm{i}=1}^{\mathrm{n}}\left(\mathrm{Q}_{\mathrm{i}}^{\text {obs }}-\mathrm{Q}_{\mathrm{i}}^{\text {sim }}\right) \times 100}{\sum_{\mathrm{i}=1}^{\mathrm{n}}\left(\mathrm{Q}_{\mathrm{i}}^{\text {obs }}\right)} \\
\mathrm{RSR}=\frac{R M S E}{S T D E V_{\text {obs }}}=\frac{\sqrt{\sum_{\mathrm{i}=1}^{\mathrm{n}}\left(\mathrm{Q}_{\mathrm{i}}^{\text {obs }}-\mathrm{Q}_{\mathrm{i}}^{\text {sim }}\right)^{2}}}{\sqrt{\sum_{\mathrm{i}=1}^{\mathrm{n}}\left(\mathrm{Q}_{\mathrm{i}}^{\text {obs }}-\overline{\mathrm{Q}}\right)^{2}}}
\end{gathered}
$$

Tiêu chuẩn đánh giá (7) - (8) theo từng chỉ số trên được thể hiện trong [21, 31].

\section{Kết quả và thảo luận}

Trong khuôn khổ nghiên cứu này, mô phỏng thủy lực và truyền mặn cho một năm 2018 được thực hiện nhằm ra mối liên hệ giữa phạm vi truyền mặn với yếu tố triều phía biển và lưu lượng nước phía thượng nguồn. Kết quả này được thực hiện trong những năm gần đây và kế thừa từ các kết quả trước, đặc biệt là dựa trên bộ thông số thủy văn được thiết lập [21] cho khu vực nghiên cứu. Mô hình NAM được ứng dụng tạo ra biên lưu lượng cho sông Vệ cho đủ một năm 2018. Từ chuỗi số liệu này đã tìm được tháng với lưu lượng dòng chảy trung bình nhỏ nhất, lớn nhất. Đã chọn ra 2 tháng là 7,12 để phân tích tương quan giữa phạm vi, mức độ truyền mặn với lưu lượng và chế độ triều. MIKE $3 \mathrm{HD}, \mathrm{AD}$ được áp dụng chạy thủy lực và mặn trong phạm vi nghiên cứu. Từ kết quả này đã thực hiện biện luận mối quan hệ giữa phạm vi truyền mặn với chế độ triều, lưu lượng dòng chảy. Lý do chọn tháng 7 mang tính đại diện cho mùa khô và tháng 12 đại diện cho mùa mưa. Trong mục này, trước tiên là trình bày kết quả hiệu chỉnh kiểm định các mô đun trong MIKE 3 được sử dụng, sau đó trình bày kết quả mô phỏng diễn biến mặn tại 2 mặt cắt MC0, MC3.

\subsection{Hiệu chỉnh và kiểm định}

Việc thiết lập mô hình MIKE 3 là cần thiết để đảm bảo kết quả mô phỏng theo kịch bản. Nghiên cứu này kế thừa một số kết quả từ các nghiên cứu trước của nhóm tác giả [20-21]. Cụ thể như sau, bộ thông số thủy văn, thủy lực cho khu vực nghiên cứu, đặc biệt kết quả từ [21] cho phép sử dụng NAM tạo biên lưu lượng trên thượng nguồn nhằm đáp ứng yêu cầu MIKE 3 HD. Trong [21] đã thực hiện bước hiệu chỉnh, kiểm định bộ thông số thủy lực cho MIKE 21 $\mathrm{HD}$, còn trong [20] đã dựa vào kết quả thủy lực này để đánh giá phạm vi và mức độ truyền mặn 
bằng MIKE $21 \mathrm{AD}$. Trong mục này, bước hiệu chỉnh, kiểm định MIKE 3 HD, kiểm định MIKE $3 \mathrm{AD}$ được thực hiện dựa trên bộ số liệu thực đo được trình bày trong mục 2.3.3.

Kết quả kiểm định và hiệu chỉnh MIKE 3 HD như sau: kết quả hiệu chỉnh tại mặt cắt $\mathrm{MC0}$ cho $\mathrm{R}^{2}=0,754$, Nash $=0,609$, PBIAS $=-2,607$, RSR $=0,624$; mặt cắt $\mathrm{MC} 3$ cho $\mathrm{R}^{2}=0,906$, Nash $=0,861$, PBIAS $=-2,688, \mathrm{RSR}=0,371$; mặt cắt $\mathrm{MC4}$ cho $\mathrm{R}^{2}=0,956$, Nash $=0,814$, PBIAS $=6,476, \mathrm{RSR}=3,062$. Kết quả kiểm định tại mặt cắt $\mathrm{MC} 0$ cho $\mathrm{R}^{2}=0,963, \mathrm{Nash}=$ 0,857 , PBIAS $=-12,275$, RSR $=0,378$; mặt cắt $\mathrm{MC} 3$ cho $\mathrm{R}^{2}=0,946$, Nash $=0,823$, PBIAS $=$ $-5,351$, RSR $=0,401$; mặt cắt $\mathrm{MC} 4$ cho $\mathrm{R}^{2}=0,949$, Nash $=0,845$, PBIAS $=0,431$, RSR $=$ 0,388. Bước hiệu chỉnh, kiểm định MIKE 3 HD được thể hiện trên hình 3 . Kết quả của mục này là chọn bộ thông số thủy lực đoạn sông Vệ cho MIKE $3 \mathrm{HD}$, trong phạm vi nghiên cứu: hệ số nhớt (eddy viscosity coefficient) bằng $0,28\left(\mathrm{~m}^{2} / \mathrm{s}\right)$ và hệ số chiều cao nhám (roughness height coefficient $\mathrm{k}_{\mathrm{s}}, \mathrm{m}$ ) là $0,1(\mathrm{~m})$. Kết quả hiệu chỉnh và kiểm định thủy lực trên được đánh giá trong phạm vi từ tốt tới rất tốt, cho phép mô phỏng truyền mặn bằng $\mathrm{MIKE} 3 \mathrm{AD}$, chỉ có duy nhất chỉ tiêu RSR tại mặt cắt số 4 là không đạt.

Kết quả kiểm định MIKE $3 \mathrm{AD}$ được thực hiện với bộ số liệu thực đo mặn 48 giờ liên tục cho 2 ngày 7-8/10/2018 tại 3 mặt cắt $\mathrm{MC} 0, \mathrm{MC} 3, \mathrm{MC} 4$ (mục 2.3.3) được thể hiện trên Hình 4. Kết quả đặc biệt phù hợp tại mặt cắt $\mathrm{MC} 0$ với 4 chỉ tiêu $\mathrm{R}^{2}=0,825$, Nash $=0,798$, PBIAS $=$ 6,919, RSR = 0,524. Tại 2 mặt cắt còn lại, $\mathrm{MC} 3$ cho $\mathrm{R}^{2}=0,728$, Nash $=0,704$, PBIAS = $1,125, \mathrm{MC} 4$ cho $\mathrm{R}^{2}=0,752$, Nash $=0,705, \mathrm{PBIAS}=-0,265$. Riêng chỉ tiêu RSR tại 2 mặt cắt MC3, MC 4 cho kết quả gần với mức đạt (tương ứng $0,781,0,711$ so với mức đạt là 0,7 ). Kết quả này cho phép khẳng định MIKE $3 \mathrm{AD}$ có thể áp dụng để mô phỏng bức tranh truyền mặn cho nghiên cứu này.

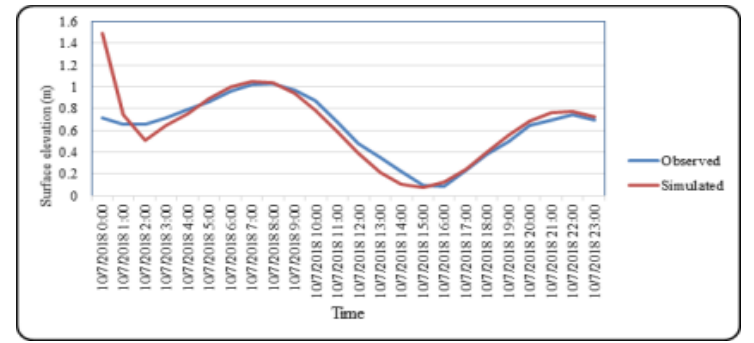

(a)

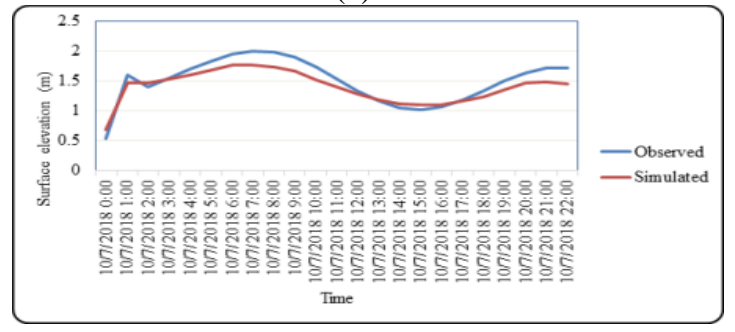

(c)

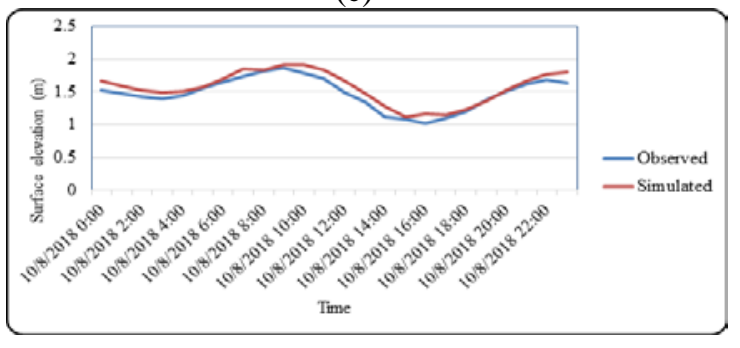

(e)

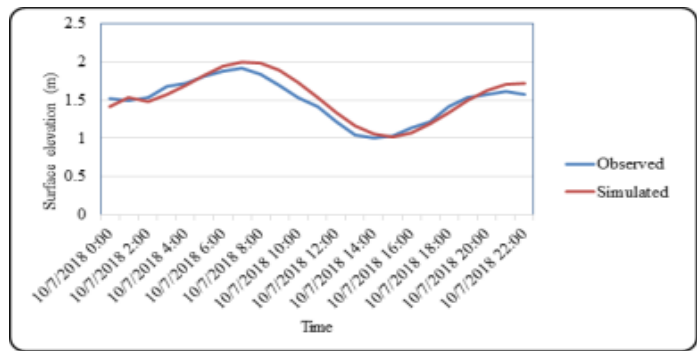

(b)

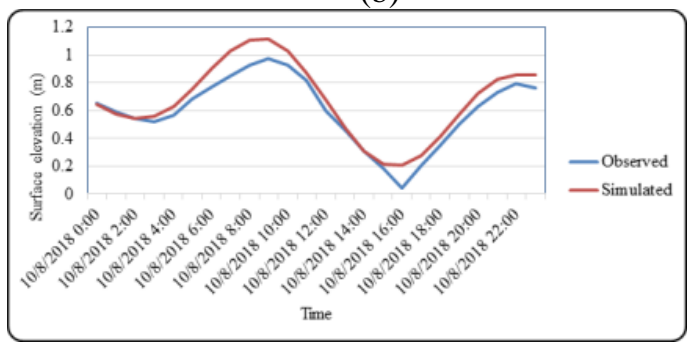

(d)

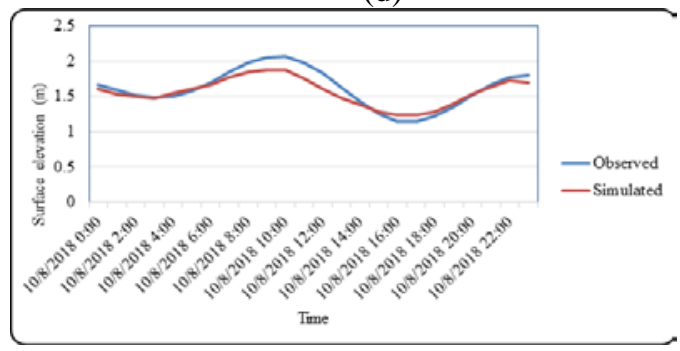

(f)

Hình 5. Biểu đồ mực nước lúc hiệu chỉnh, kiểm định MIKE 3 HD tại 3 vị trí mặt cắt $\mathrm{MC} 0, \mathrm{MC} 3, \mathrm{MC} 4$ MIKE 3: (a), (c), (e) Hiệu chỉnh; (b), (d), (f) Kiểm định. 


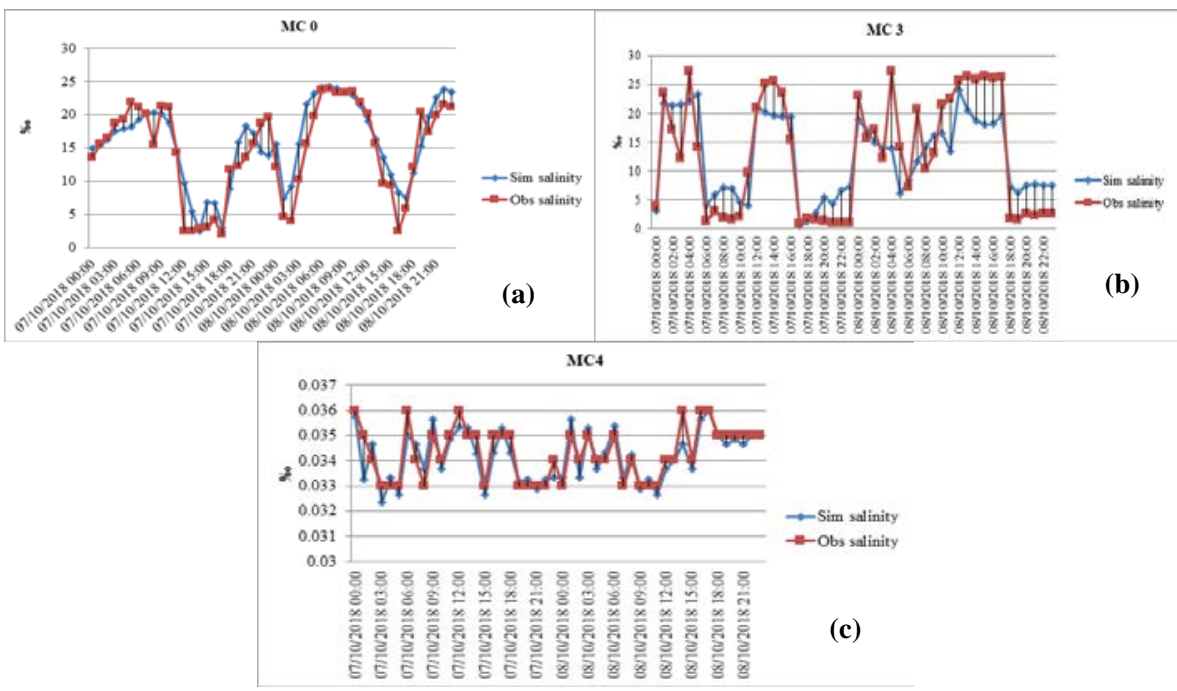

Hình 6. So sánh độ mặn giữa giá trị đo và chạy mô hình MIKE 3 tại các mặt cắt: (a) MC0, (b) MC3; (c) MC4.

\subsection{Sụ phụ thuộc truyền mặn vào luu luợng}

Lưu lượng dòng chảy vào mùa khô rất nhỏ, tháng được chọn 7/2018 có biên độ dao động trong khoảng từ $0-13,13$ m³/s. Đây là tháng có lưu lượng trung bình nhỏ nhất của năm 2018 . Đã thực hiện so sánh kết quả mô phỏng mặn thời điểm $Q_{\max }$ và $\mathrm{Q}_{\min }$ của tháng 7.

Thời điểm $Q_{\min }$ có lưu lượng nhỏ nhất trong tháng $7 / 2018$ là 2,175 m³/s rơi vào ngày $20 / 7$. Kết quả tính toán cho thấy độ mặn trong tháng 7 ứng với $Q_{\min }$ dao động trong khoảng 30,5$32,5 \%$ ở $\mathrm{MC0}$ và $8,5-30 \%$ ở $\mathrm{MC} 3$. Trong khoảng thời gian từ ngày $8-12 / 07 / 2018$ độ mặn có xu hướng giảm dần, tuy không đáng kể, trong khoảng $30 \%$ ở $\mathrm{MC} 0$ và $20 \%$ ở $\mathrm{MC} 3$, do lưu lượng tăng, tuy không lớn. Có thể lưu ý tới bất thường trong các ngày $3-4 / 7 / 2018$, dù $\mathrm{Q}_{\text {min }}$ có giảm nhưng nồng độ tại $\mathrm{MC} 3$ có tăng có thể giải thích do tác động phụ của yếu tố triều.

Thời điểm $Q_{\max }$ có lưu lượng lớn nhất trong tháng $7 / 2018$ là $13,1338 \mathrm{~m}^{3} / \mathrm{s}$. Kết quả mô phỏng cho độ mặn nằm trong khoảng $30-32 \%$ ở $\mathrm{MC} 0$ và $5-29 \%$ ở $\mathrm{MC} 3$, phổ có thấp hơn so với thời điểm $Q_{\min }$. Vào khoảng các ngày từ 7 đến 13/07/2018 với lưu lượng cao hơn so với lưu lượng trung bình, độ mặn có xu hướng giảm nhẹ nhưng không đáng kể do lưu lượng tăng nhẹ, ổn định ở khoảng $32 \%$ ở $\mathrm{MC} 0$ và $17 \%$ ở MC3. Có thể lưu ý tới bất thường trong các ngày 3-4/7/2018, dù $\mathrm{Q}_{\max }$ có giảm nhưng nồng độ tại $\mathrm{MC} 0, \mathrm{MC} 3$ có tăng là do tác động phụ của yếu tố triều.
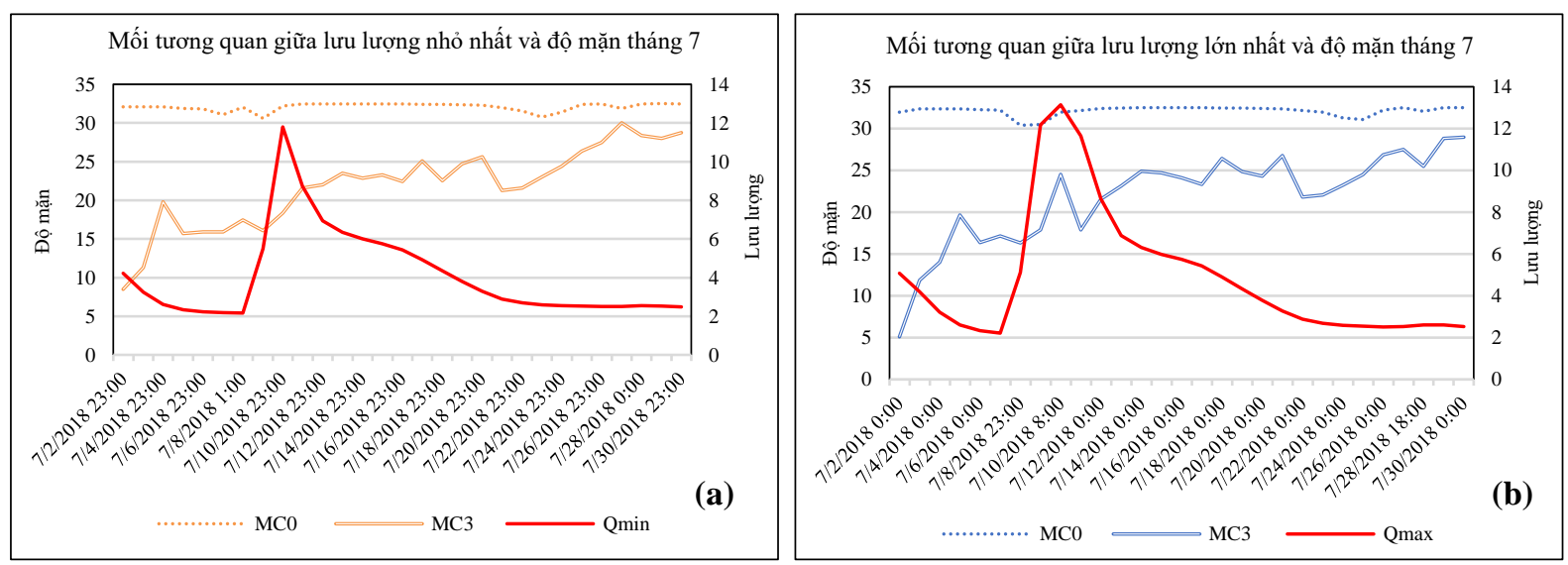

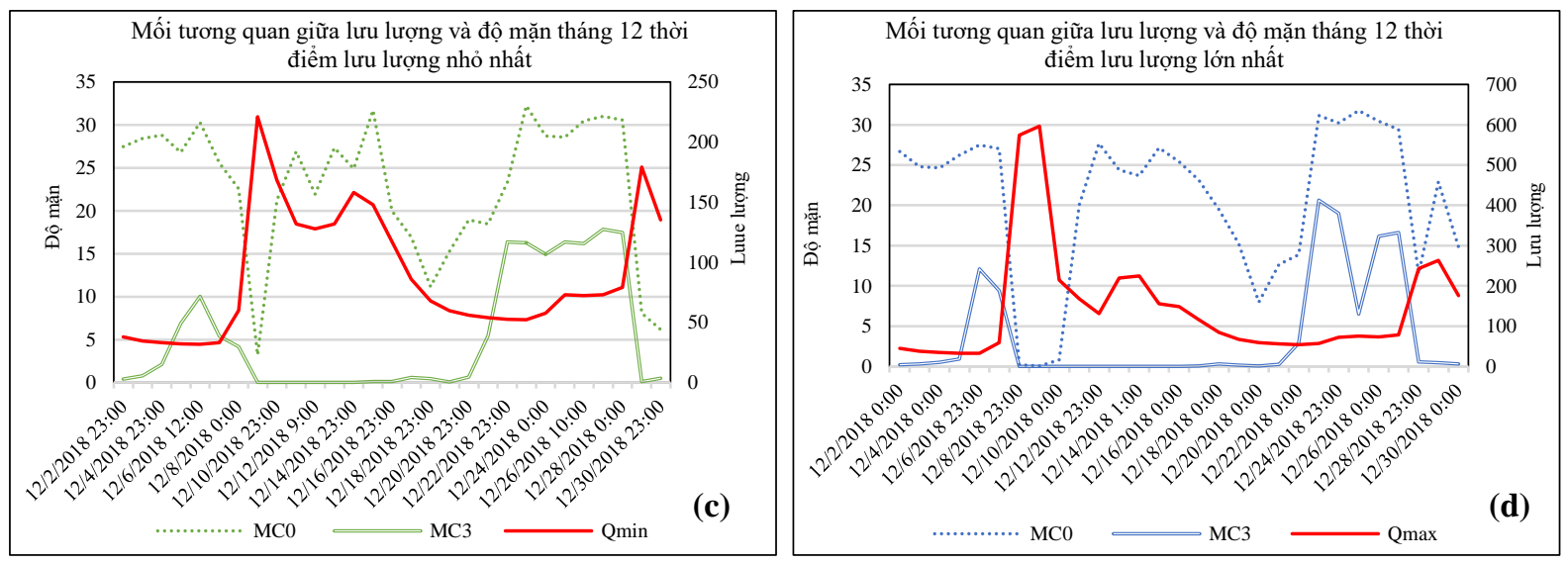

Hình 7. Tương quan lưu lượng và độ mặn, mùa khô (a, b) tháng 7/2018 mùa mưa (c, d) tháng 12/2018.

Thời điểm $Q_{\min }$ có lưu lượng nhỏ nhất trong tháng 12 là $31,815 \mathrm{~m}^{3} / \mathrm{s}$. Độ mặn trong tháng 12 thời điểm lưu lượng nhỏ nhất giao động trong khoảng 3-32\% ở $\mathrm{MC} 0$ và $0-17 \% 0$ ở $\mathrm{MC} 3$. Riêng vào các ngày 7 đến 12/12/2018 với lưu lượng lên đến gần $250 \mathrm{~m}^{3} / \mathrm{s}$ thì độ mặn giảm rõ rệt còn $20-25 \%$ ở $\mathrm{MC} 0$ và $0,02-1 \% 0$ ở $\mathrm{MC} 3$. Có thể lưu ý tới bất thường trong các ngày $4-$ 5/12/2018, dù $\mathrm{Q}_{\min }$ có giảm nhưng nồng độ tại $\mathrm{MC} 0, \mathrm{MC} 3$ có tăng là do tác động phụ của yếu tố triều.

Thời điểm $\mathrm{Q}_{\max }$ có lưu lượng lớn nhất trong tháng 12 là 596,002 $\mathrm{m}^{3} / \mathrm{s}$. Độ mặn trong thời điểm này nằm trong khoảng $0,5-31 \%$ ở $\mathrm{MC} 0$ và $0-20 \%$ ở $\mathrm{MC} 3$. Kết quả này là nhỏ hơn so với thời điểm $Q_{\text {min }}$ của cũng trong tháng 12 nhiều. Vào các ngày 7 đến 9/12/2018 lưu lượng lên đến gần $600 \mathrm{~m}^{3} / \mathrm{s}$ thì độ mặn ở MC 0 chỉ còn khoảng $0,02-0,5 \%$, MC3 chỉ còn khoảng $0,02 \%$, tức là mặn truyền vào $\mathrm{MC} 0$ được khoảng $500 \mathrm{~m}$ thì bằng 0 . Có thể lưu ý tới bất thường trong các ngày 4-5/12/2018, dù $\mathrm{Q}_{\max }$ có giảm nhưng nồng độ tại $\mathrm{MC} 0, \mathrm{MC} 3$ có tăng là do tác động phụ của yếu tố triều.

Có thể kết luận rằng, yếu tố lưu lượng tác động tới xâm nhập mặn vùng cửa sông Vệ. Sự tăng độ mặn tại cửa sông $\mathrm{MC} 0$ diễn ra khi $\mathrm{Q}$ có xu thế giảm và ngược lại khi $\mathrm{Q}$ tăng, độ mặn tại $\mathrm{MC} 0$ có xu thế giảm. Tương tư như vậy tại $\mathrm{MC} 3$, nhưng có sự khác biệt tại một số thời điểm và biên độ (Hình 7).

\subsection{Sự phu thuộc phạm vi truyền mặn vào chế độ triều và luu luợng}

Trong biện luận, độ mặn được chọn là mức $1 \% 00$ và cột mốc $\mathrm{MC} 0$ để biện luận. Theo đó độ mặn vượt mức 0,75 là không phù hợp với cây trồng và con người. Kết quả mô phỏng vào ngày $20 / 7 / 2018$ cho thấy từ $0-3 h$, khi triều xuống (Hình $8 \mathrm{a}$ ), lưu lượng phía thượng nguồn rất nhỏ, hướng dòng chảy vẫn đi từ biển vào sông, có nghĩa là không chịu tác động của lưu lượng. Trong khoảng thời gian này, độ mặn tăng dần khi đi qua $\mathrm{MC} 0$ và truyền vào phía sông, lúc $0 \mathrm{~h}$ mặn, mức $1 \%$ o truyền tới vị trí $2,9 \mathrm{~km}$ (Hình $8 \mathrm{~b}$ ), đến $3 \mathrm{~h}$ mặn truyền sâu vào $3,1 \mathrm{~km}$ (Hình 8 c). Khoảng thời gian tiếp theo, từ $4-8 \mathrm{~h}$ triều lên, hướng dòng chảy có sự đổi hướng, truyền từ sông ra biển, phạm vi truyền mặn giảm, tới $8 \mathrm{~h}$ rút xuống vị trí $2,85 \mathrm{~km}$ (Hình $8 \mathrm{~d}$ ). Khoảng thời gian 8-14h, triều tuy xuống, độ mặn vẫn truyền vào đất liền đến $14 \mathrm{~h}$ đã truyền được từ 2,85 $\mathrm{km}$ lên $3,05 \mathrm{~km}$ (Hình $8 \mathrm{e}, 8 \mathrm{f})$. Thời gian còn lại trong ngày từ 14-23 là lúc triều lên, hướng dòng chảy từ sông ra biển, độ mặn giảm dần, mặn truyền vào $3,05 \mathrm{~km}$ lúc $14 \mathrm{~h}$ nhưng đến $23 \mathrm{~h}$ chỉ còn $2,95 \mathrm{~km}$. Có thể thấy rằng, mực nước khoảng $14-23 \mathrm{~h}$ cao hơn mực nước khoảng 5-8h nên mặn truyền sâu hơn thời điểm 5-8h, khoảng $100 \mathrm{~m}$. Như vậy, vào ngày $20 / 07$, mặn truyền vào phía đất liền, dao động trong khoảng 2,9-3,1 km tính từ cửa sông. Thời điểm mặn truyền sâu nhất vào lúc $3 \mathrm{~h}$ sáng, đạt mốc $3,1 \mathrm{~km}$, đây là thời điểm triều bắt đầu dâng lên lần đầu tiên trong ngày. 
Vào mùa khô, hướng dòng chảy chủ yếu chịu tác động bởi chế độ triều, ít chịu ảnh hưởng của lưu lượng, mặn chỉ bị ảnh hưởng chủ yếu bởi chế độ thuỷ triều.

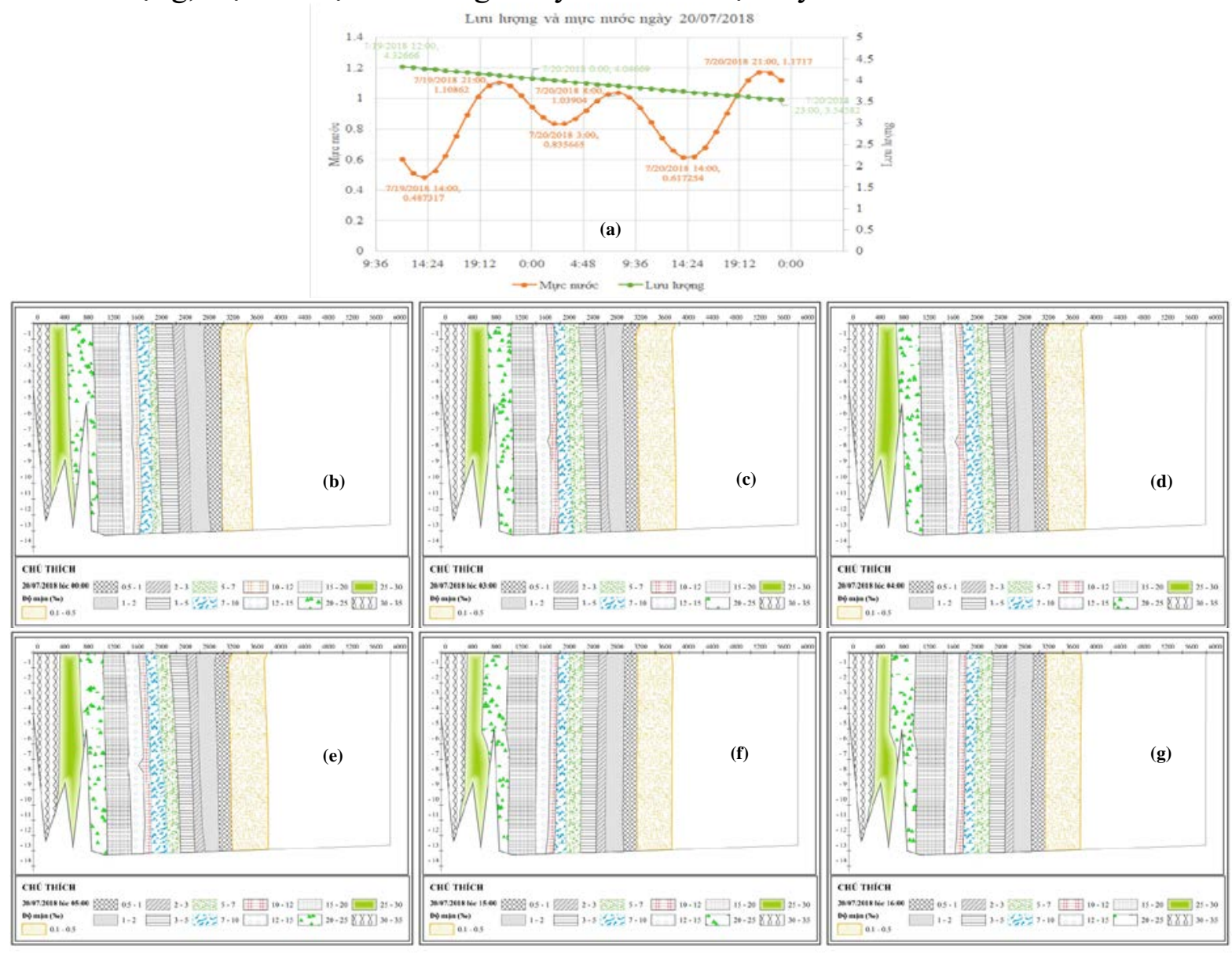

Hình 8. Sự phụ thuộc giữa hướng dòng chảy, mức độ, phạm vi truyền mặn với chế độ triều, lưu lượng dòng chảy vào mùa khô (a) biểu đồ lưu lượng-mực nước; (b) Phạm vi truyền mặn lúc $0 \mathrm{~h}$ đạt 2,9 km; (c) Phạm vi truyền mặn lúc $3 \mathrm{~h}$ đạt $3,1 \mathrm{~km}$; (d) Phạm vi, mức độ truyền mặn lúc $4 \mathrm{~h}$, thời điểm dòng chảy có sự chuyển hướng từ sông ra biển, phạm vi đạt mốc $3,08 \mathrm{~km}$; (e) Phạm vi truyền mặn lúc $5 \mathrm{~h}$, thời điểm dòng chảy theo hướng từ sông ra biển, đạt đạt 3,05 km; (f) Phạm vi truyền mặn lúc $15 \mathrm{~h}$, thời điểm dòng chảy bắt đầu chuyển hướng, đạt $3,05 \mathrm{~km}$; (g) Phạm vi lúc $16 \mathrm{~h}$, thời điểm dòng chảy hướng từ biển vào sông, đạt $3,07 \mathrm{~km}$.

Trong trường hợp mùa mưa, trên Hình $9 \mathrm{a}$, cho thấy từ $0-15 \mathrm{~h}$, mực nước lên dần, hay nói cách khác triều đang lên, tuy nhiên do lưu lượng dòng chảy lớn (300-596 m³ $/ \mathrm{s})$, kết quả chạy $\mathrm{HD}$ cho thấy dòng chảy theo hướng từ sông ra biển. Từ $0-15 \mathrm{~h}$, kết quả chạy $\mathrm{AD}$ cho thấy mặn chưa truyền vào $\mathrm{MC} 0$, tại đây chỉ giữ mức $0,01-0,1 \%$. Trong khoảng $0-9 \mathrm{~h}$, mặn tăng, giảm phức tạp trong $0,007-0,04 \%$, độ chênh lệch nhau nằm khoảng $0,01 \%$. Đến $10-12 \mathrm{~h}$, mặn có xu hướng tăng mạnh tại mặn cắt $\mathrm{MC} 0$, đến $12 \mathrm{~h}$ tăng lên mức $0,2691 \%$. Từ $12-15 \mathrm{~h}$, mặn giảm dần đến $15 \mathrm{~h}$ mặn tại $\mathrm{MC} 0$ chỉ còn $0,1 \%$. Từ $16-23 \mathrm{~h}$ mặn bắt đầu xâm nhập về phía $\mathrm{MC} 0$, tuy hướng dòng chảy vẫn giữ từ sông ra biển: từ 16-19h mặn tại $\mathrm{MC} 0$ tăng nhanh do lưu lượng đang giảm đáng kể, từ $300 \mathrm{~m}^{3} / \mathrm{s}$ giảm còn $254 \mathrm{~m}^{3} / \mathrm{s}$, tới $19 \mathrm{~h}$ độ mặn tại $\mathrm{MC} 0$ đạt cực đại là $10 \%$ và truyền sâu khoảng $200 \mathrm{~m}$ (mức $1 \%$ ). Từ $20-23 \mathrm{~h}$, mặn giảm dần, đến $23 \mathrm{~h}$, mặn tại mặt cắt $\mathrm{MC} 0$ giảm còn $3,22 \%$ và chỉ còn truyền sâu $90 \mathrm{~m}$ thì bằng $1 \%$. Có thể thấy mùa mưa, mặn đồng thời chịu tác động của chế độ triều và lưu lượng thượng nguồn (Hình 9b-9d).

Độ mặn tại MC0 giao động từ $0,01-10 \%$, độ mặn cao nhất trong ngày 09/12/2018 là vào $19 \mathrm{~h}$ với $10 \%$ và thấp nhất là $0,01 \%$ lúc $7 \mathrm{~h}$. Độ mặn ở MC0 từ $0-15 \mathrm{~h}$ luôn giữ nhỏ hơn $1 \%$ và lưu lượng đầu nguồn luôn lớn hơn $300 \mathrm{~m}^{3} / \mathrm{s}$. Đến 16-23h, độ mặn ở MC0 tăng mạnh, luôn 
lớn hơn $1 \%$ và lưu lượng đầu nguồn lúc này giảm nhỏ hơn $300 \mathrm{~m}^{3} / \mathrm{s}$. Ở trường hợp này, ta nhận thấy rất rõ mối tương quan giữa lưu lượng, chế độ triều và phạm vi truyền mặn (Hình 9).
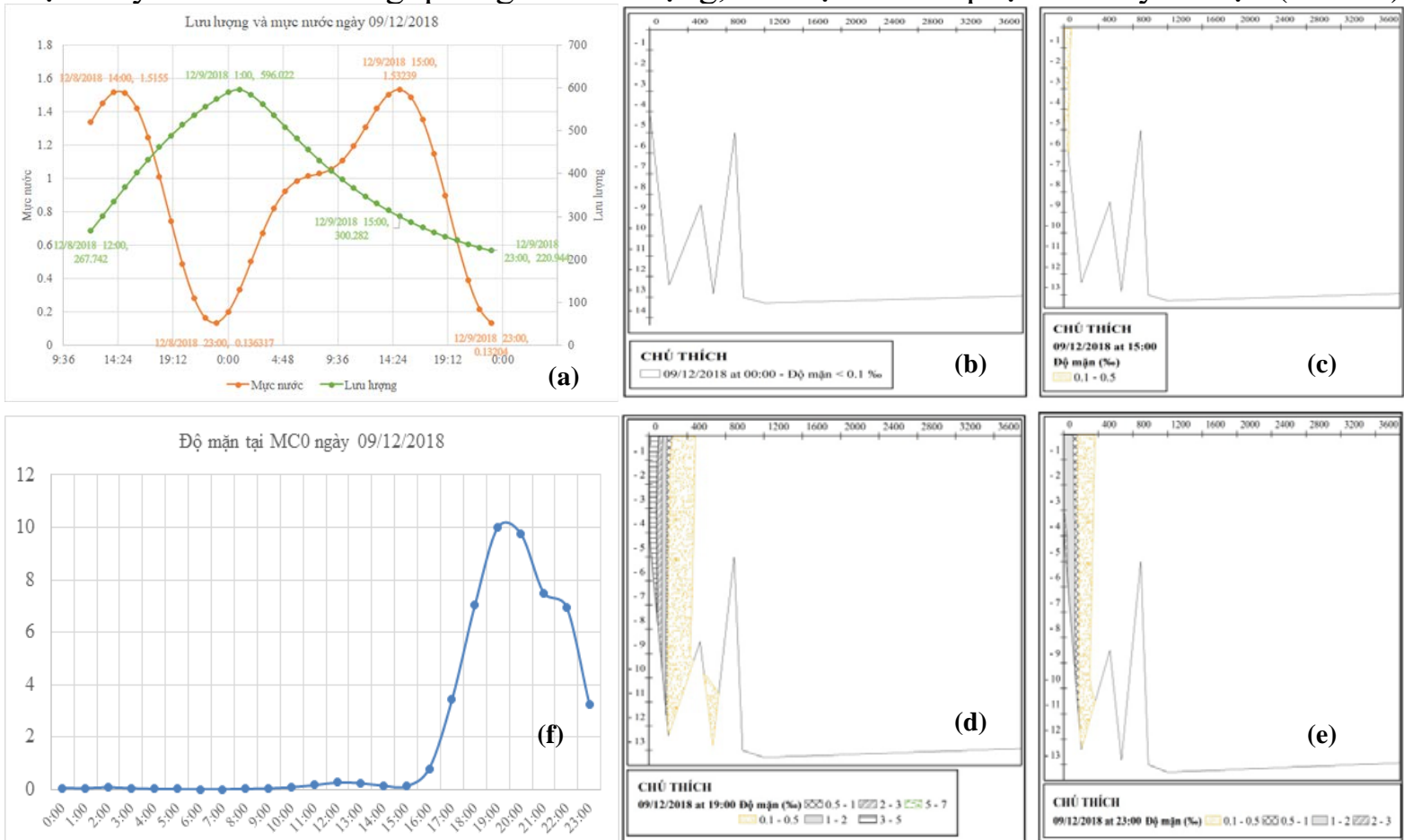

Hình 9. Sự phụ thuộc giữa hướng dòng chảy, mức độ, phạm vi truyền mặn với chế độ triều, lưu lượng dòng chảy vào mùa mưa: (a) chế độ triều và lưu lượng ngày 9/12/2018; (b) Phạm vi, mức độ truyền mặn lúc $0 \mathrm{~h}$. (mặn vẫn chưa truyền vào $\mathrm{MC0}$ (mức 10/00) độ mặn lớn nhất thời điểm này là $0,03750 / 00$ ); (c) Phạm vi truyền mặn lúc 15h, mặn vẫn chưa truyền tới MC0 (mức 10/00) nhưng độ mặn tăng lên 0,1650/00;(d) Phạm vi truyền mặn lúc 19h, mặn truyền vào $200 \mathrm{~m}$ tính từ $\mathrm{MC0}$ (mức 10/00); (e) Phạm vi truyền mặn lúc 23h, mặn truyền vào 90 m tính từ $\mathrm{MC0}$ (mức 10/00); (f) Biểu đồ diễn biến độ mặn tại MC0 ngày 09/12/2018, trục tung 0/00.

\subsection{Sư biến đổi biên độ mặn tại cưa sông-biển}

Trong trường hợp mùa khô trên Hình 10a, 10b, độ mặn tại mặt cắt MC0 giao động trong khoảng $(31-32,4 \%$ ), nồng độ giảm (rất nhỏ) chủ yếu do mặn được triều đẩy vào phía sâu, vai trò của lưu lượng (thời điểm này) là rất bé. Do vậy, có thể khẳng định vào mùa khô, biên độ mặn tại $\mathrm{MC0}$ thay đổi rất bé và được đẩy vào sâu đất liền do yếu tố triều. Vào mùa mưa trên Hình $10 \mathrm{c}, 10 \mathrm{~d}$, biên độ mặn tại $\mathrm{MC} 0$ thay đổi lớn hơn nhiều $(1-11 \% 0)$. Có thể thấy rõ mặn tại MC0 tăng trùng với thời điểm triều xuống và lưu lượng tăng. Tới khi lưu lượng phía thượng nguồn giảm dần cùng với triều dâng, có một khoảng thời gian dài, độ mặt tại $\mathrm{MC} 0$ gần như biến mất, sau đó khi triều độ mặn tăng dần do lưu lượng phía thượng nguồn khá lớn. Do vậy, có thể kết luận, vào mùa mưa độ mặn tại $\mathrm{MC} 0$ chịu ảnh hưởng phần lớn bởi lưu lượng, tuy nhiên yếu tố triều có vai trò điều tiết nhất định. 


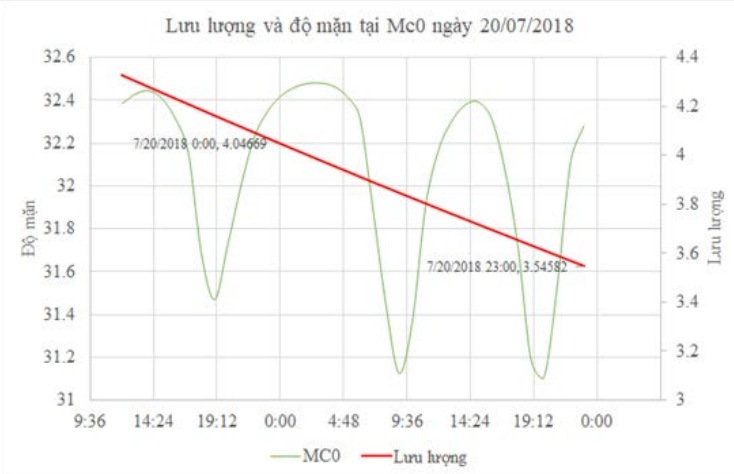

(a)

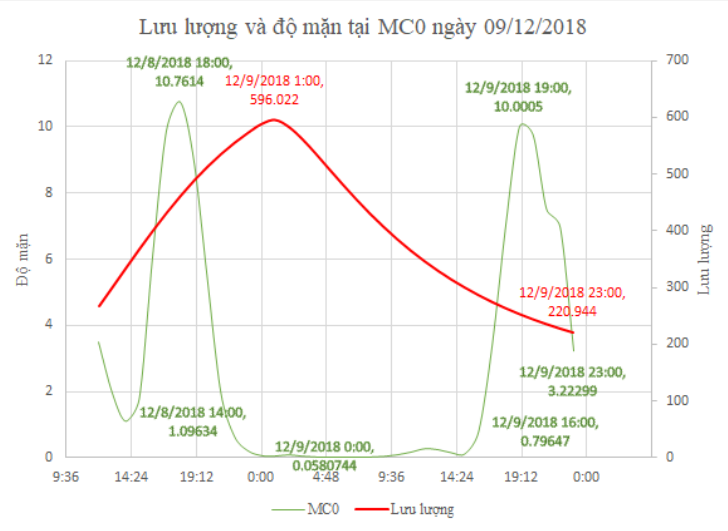

(c)

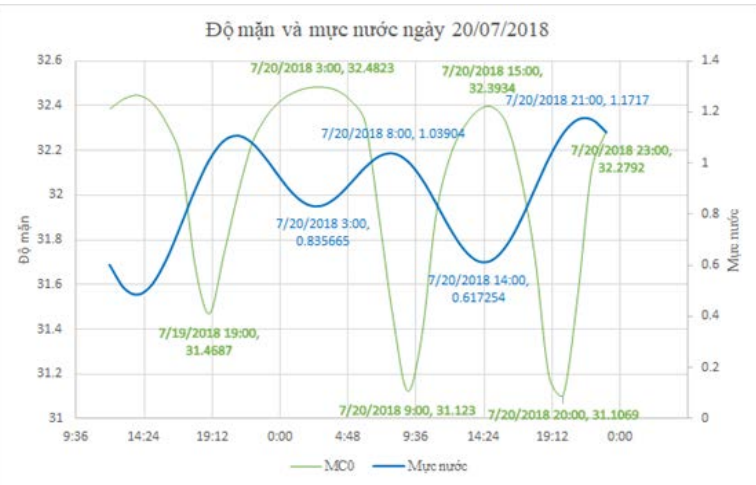

(b)

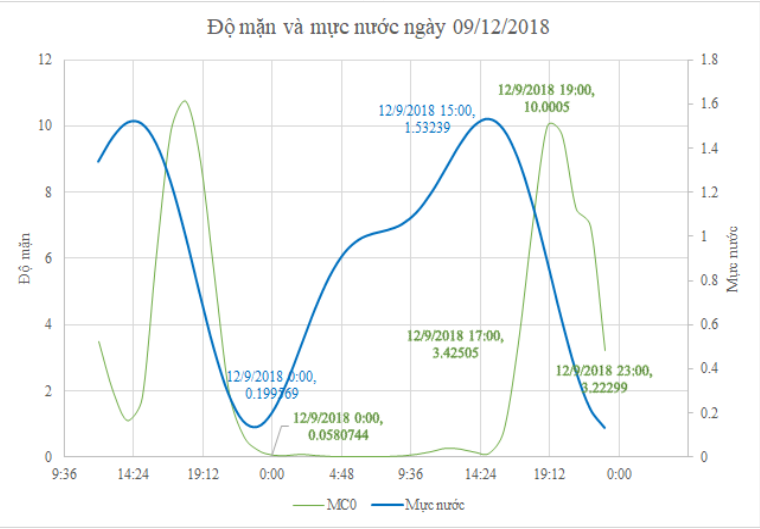

(d)

Hình 10. Sự phụ thuộc giữa độ mặn tại 2 vị trí đo $\mathrm{MC} 0$ vào chế độ triều và lưu lượng cho mùa khô (a, b) và mùa mưa $(c, d)$.

\section{Kết luận}

Các kết quả đạt được trong nghiên cứu này gồm:

Thứ nhất, đã thực hiện hiệu chỉnh, kiểm định mô hình MIKE 3 HD. Kết quả là lựa chọn được bộ thông số thủy lực: hệ số nhớt bằng $0,28\left(\mathrm{~m}^{2} / \mathrm{s}\right)$ và hệ số chiều cao nhám là $0.1(\mathrm{~m})$. Đã thực hiện kiểm định kết quả mô phỏng mặn MIKE $3 \mathrm{AD}$ tại các mặt cắt $\mathrm{MC} 0, \mathrm{MC} 3, \mathrm{MC} 4$ với kết quả đạt yêu cầu. Kết quả mục này thể hiện trong 3.1.

Thứ hai, đã tìm ra mối tương quan giữa độ mặn tại các vị trí $\mathrm{MC} 0$ gần biển, $\mathrm{MC} 3$, cách đó $490 \mathrm{~m}$ với lưu lượng thượng nguồn cho mùa mưa và mùa khô. Sự tăng độ mặn tại vị trí $\mathrm{MC} 0$, cửa sông $\mathrm{MC} 0$ diễn ra khi $\mathrm{Q}$ có xu thế giảm và ngược lại khi $\mathrm{Q}$ tăng, độ mặn tại $\mathrm{MC} 0$ có xu thế giảm. Tương tư như vậy tại $\mathrm{MC} 3$, nhưng có sự khác biệt tại một số thời điểm và biên độ lớn hơn tại MC0. Kết quả này được trình bày trong mục 3.2 .

Thứ ba, làm rõ sự phụ thuộc giữa phạm vi truyền mặn vào chế độ triều và lưu lượng cho 2 mùa mưa và khô, đã chỉ ra thời điểm mặn truyền vào sâu nhất. Có thể thấy vào mùa khô, xâm nhập mặn chịu chi phối lớn hơn bởi chế độ triều, ít chịu ảnh hưởng của lưu lượng. Vào mùa mưa, mặn truyền vào không sâu như mùa khô, chỉ đi được quãng đường bằng $6 \%$ so với mùa khô. Điều này cho thấy vào mùa khô, phạm vi truyền mặn được quyết định bởi lưu lượng thấp và chi phối bởi chế độ triều. Kết quả này được trình bày trong mục 3.3.

Thứ tư, đã chỉ ra tương quan giữa độ mặn với lưu lượng và chế độ triều. Cụ thể, vào mùa khô, biên độ mặn tại $\mathrm{MC0}$ thay đổi rất bé và được đẩy vào sâu đất liền do yếu tố triều, vào mùa mưa độ mặn tại MC0 nhỏ, chịu ảnh hưởng phần lớn bởi lưu lượng, tuy nhiên yếu tố triều có vai trò điều tiết nhất định. Mặt cắt $\mathrm{MC} 3$ cũng có bức tranh tương tự, tuy có khác với MC0 ở thời điểm và biên độ. Kết quả này được trình bày trong mục 3.4. 
Nghiên cứu này cũng không tránh khỏi hạn chế, do số liệu thực đo giới hạn bởi chuỗi số liệu đo 48 tiếng cho 2 ngày 7-8/10/2018 nên cần tiếp tục thực hiện kiểm định các mô hình thủy lực và truyền mặn được sử dụng. Hướng nghiên cứu tiếp theo của nghiên cứu là mô phỏng truyền mặn cho kịch bản biến đổi khí hậu, tìm ra sự phụ thuộc giữa phạm vi truyền mặn với các yếu tố thủy văn và dòng chảy.

Đóng góp của tác giả: Xây dựng ý tưởng nghiên cứu; Vạch ra sơ đồ viết bản nháp, chỉnh sửa bản thảo: B.T.L.; Xử lý số liệu, tham gia chạy mô hình MIKE 3, viết bản thảo: L.T.M.D.

Lời cảm ơn: Nghiên cứu này được thực hiện nhờ góp ý kiến từ một số nhà khoa học từ Viện Khoa học và Thủy lợi miền Nam. Bộ số liệu đo được sử dụng trong nghiên cứu được nhóm tác giả tự bỏ kinh phi đi đo trong thời gian làm luận án.

Lời cam đoan: Tập thể tác giả cam đoan bài báo này là công trình nghiên cứu của tập thể tác giả, chưa được công bố ở đâu, không được sao chép từ những nghiên cứu trước đây; không có sự tranh chấp lợi ích trong nhóm tác giả.

\section{Tài liệu tham khảo}

1. Liu, B.; Peng, S.; Liao, Y.; Wang, H. The characteristics and causes of increasingly severe saltwater intrusion in Pearl River Estuary. Estuar. Coast. Shelf Sci. 2019, 220, 54-63.

2. Werner, A.D. Seawater intrusion processes, investigation and management: Recent advances and future challenges. Adv. Water Resour. 2013, 51, 3-26.

3. Rahmawati, N.; Vuillaume, J.F.; Purnama, I.L.S. Salt intrusion in coastal and lowland areas of semarang city. J. Hydrol. 2013, 494, 146-159.

4. Haddout, S.; Igouzal, M.; Maslouhi, A. Modeling the effect of salt water intrusion in the Sebou River estuary (Morocco). Russ. Meteorol. Hydrol. 2017, 42, 803-811.

5. Pereira, C.S.; Lopes, I.; Sousa, J.P.; Chelinho, S. Effects of $\mathrm{NaCl}$ and seawater induced salinity on survival and reproduction of three soil invertebrate species. Chemosphere 2015, 135, 116-122.

6. Unno Tatsuya, Jungman Kim, Yumi Kim, Son G Nguyen, Robin B Guevarra, Gee Pyo Kim, Ji-Hoon Lee, Michael J Sadowsky. Influence of seawater intrusion on microbial communities in groundwater. Sci. Total Environ. 2015, 532, 337-343.

7. Alcérreca-Huerta, J.C.; Callejas-Jiménez, M.E.; Carrillo, L.; Castillo, M.M. Dam implications on salt-water intrusion and land use within a tropical estuarine environment of the Gulf of Mexico. Sci. Total Environ. 2019, 652, 1102-1112.

8. Tian, R. Factors controlling saltwater intrusion across multi-time scales in estuaries, Chester River, Chesapeake Bay. Estuar. Coast. Shelf Sci. 2019, 223, 61-73.

9. Alpine, A.E.; Cloern, J.E. Trophic interactions and direct physical effects control phytoplankton biomass and production in an estuary. Limnol. Oceanogr. 1992, 37, 946-955.

10. Lin, J.; Xie, L.; Pietrafesa, L.J.; Shen, J.; Mallin, M.A.; Durako, M.J.. Dissolved oxygen stratification in two micro-tidal partially-mixed estuaries. Estuar. Coast. Shelf Sci. 2006, 70, 423-437.

11. Do, M.H.T.; Thiên, Đ.Q.; An, T.T.P. Đánh giá hiện trạng và các nhân tố ảnh hưởng tới quá trình xâm nhập mặn sông Trường Giang - tỉnh Quảng Nam. Tạp chí Khí tượng Thủy văn 2011, 606, 19-24.

12. Đại, H.V.; Hiền, N.T.; Hiền, T.D. Đánh giá độ nhạy một số tham số trong mô hình mô phỏng xâm nhập mặn hệ thống sông Mã. Tạp chi Khi tượng Thủy văn 2014, 643, 24 28. 
13. Hoàng, T.T.; Vi, V.T.T.; Long, P.T. Ảnh hưởng xâm nhập mặn đến quá trình lấy nước của nhà máy nước Tân Hiệp. Tạp chí Khí tượng Thủy văn 2016, 666, 15-20.

14. Dũng, Đ.V; Phương, T.Đ; Oanh, L.T. Khai thác mô hình MIKE 11 trong dự báo, cảnh báo xâm nhập mặn vùng Đồng bằng sông Cửu Long. Tạp chí Khí tượng Thủy văn 2018, 693, 48-58.

15. Sơn, H.T; Lan, V.T.T. Biến động lan truyền mặn vùng hạ lưu sông Vu Gia - Thu Bồn dưới tác động vận hành của các công trình thủy điện Hồ. Tạp chí Khí tương Thủy văn 2018, 690, 1-11.

16. Trường, T.V.; Sách, B.N.; Tuấn, N.V. Đánh giá xâm nhập mặn vùng ven biển Bắc Bộ ứng với các kịch bản cấp nước thời kỳ đồ ải vụ Đông Xuân trên sông Hồng và đề xuất tiết kiệm nguồn nước từ các hồ chứa. Tạp chi Khi tượng Thủy văn 2019, 704, 33-48.

17. Hà, L.T; Khảm, D.V. Áp dụng mô hình thủy lực MIKE 11 để đánh giá nguy cơ xâm nhập mặn theo kịch bản nước biển dâng tỉnh Nam Định. Tạp chí Khí tượng Thủy văn 2012, 613, 32-39.

18. Sơn, H.T; Lan, V.T.T. Diễn biến xâm nhập mặn vùng hạ lưu hệ thống sông Vu Gia Thu Bồn. Tạp chí Khi Tuợng Thủy văn 2018, 686, 37-45.

19. Nhung, Đ.T.K.; Nghiêm, Đ.V. Đánh Giá Và Dự Báo Hình Thái Xâm Nhập Mặn Vùng Hạ Lưu Sông Trà Khúc - Sông Vệ. Khoa Học Kỹ Thuật Thủy Lợi Và Môi Truờng 2020, 50, 119-126.

20. Diep, L.; Long, B. Application of MIKE/SWAT for simulation the salt intrusion - a case study in Ve river, Quang Ngai province. Lowl. Technol. Int. 2020, 22, 258-267.

21. Diep, L.T.M.; Anh, B.H.; Long, B.T. Applying mathematical models SWAT/NAM/MIKE to build hydrological and hydrodynamics parameters for flow calculation - in case of Ve river, Quang Ngai. VN J. Hydrometeorol. 2019, 700, 1-12.

22. Hưng, N.Q. Đánh giá mức độ xâm nhập mặn hạ lưu sông Cả dưới tác động biến đổi khí hậu. Tạp chí Khí tượng Thủy văn 2016, 663, 47-54.

23. Wei, C.; Chen, K.; Kuang, C.; Zhud, D.Z.; Hee, L.; Mao, X.; Liang, H.; Song, H.L. Influence of sea level rise on saline water intrusion in the Yangtze River Estuary, China. Appl. Ocean Res. 2016, 54, 12-25.

24. Moharir, R.V.; Khairnar, K.; Paunikar, W.N. MIKE 3 as a modeling tool for flow characterization: A review of applications on water bodies. Int. J. Adv. Stud. Comput. Sci. Eng. 2014, 3, 32-43.

25. Safavi, S.; Saghafian, B.; Hosseini, S.A. Characterizing flow pattern and salinity using the 3D MIKE 3 model: Urmia Lake case study. Arab. J. Geosci. 2020, 13. https://doi.org/10.1007/s12517-020-5095-4.

26. DHI, MIKE 11, 2005.

27. DHI, MIKE 21 \& MIKE 3. Flow model FM, Hydrodynamic and Transport Module, Scientific Documentation, 2018.

28. DHI, MIKE 21 \& MIKE 3. Flow Model FM Advection - Dispersion Module, Scientific Documentation, 2013.

29. GEBCO. Online Available: https://www.gebco.net/.

30. Ninh, P.V. Hydrometeorology and marine dynamics. In East sea, Ha Noi: Natural science and technology publishing house, 2009, pp. 644.

31. Moriasi, D.N.; Arnold, J.G.; Van Liew, M.W.; Bingner, R.L.; Harmel, R.D.; Veith, T.L. Model evaluation guidelines for systematic quantification of accuracy in watershed simulations. Agric. Biol. Eng. 2007, 50, 885-900.

32. Wang, Y.; Jiang, H.; Zhang, X.; Jin, J. Spatial and temporal distribution of sea surface salinity in coastal waters of china based on Aquarius. IOP Conf. Ser.: Earth Environ. Sci. 2014, 17, 31-36. https://doi.org/10.1088/1755-1315/17/1/012116. 
33. Yang, Y.; Xiang, R.; Liu, J.; Tang, L. Inconsistent sea surface temperature and salinity changing trend in the northern South China Sea since $7.0 \mathrm{ka}$ BP. J. Asian Earth Sci. 2019, 171, 178-186. https://doi.org/10.1016/j.jseaes.2018.05.033.

\title{
Modelling the dependence between salinity intrusion and
} hydrological factors using MIKE 3: a case study of Ve river, Quang Ngai

\author{
Bui Ta Long1* ${ }^{*}$ Le Thi My Diep ${ }^{2}$ \\ ${ }^{1}$ Ho Chi Minh City University of Technology; longbt62@hcmut.edu.vn \\ ${ }^{2}$ Southern Institute of Water Resources Research; diepmoitruongmdquangngai@gmail.com
}

\begin{abstract}
Salt intrusion has received particular attention over the years due to its negative impact on socio-economic development, especially in the Mekong Delta. There have been many programs, research topics in this area, in which most of the research was carried out using the MIKE 11 model to calculate the intrusion salt level. The results obtained were focused on clarifying the range of salinity in relation to the distance from the estuary, with little attention paid to the mechanism of salinity transfer (by the surface or bottom). The dependence of the range of salinity transfer on hydrological and tidal regime has not received due attention. In addition, the number of studies on salt intrusion in the central provinces is much limited, which leads to many scientific and practical problems that have not yet been discovered. In this study, the MIKE 3 model is used to elucidate the salinity mechanism transfer from sea to river, as well as the salinity range dependence on flow factors (river), tidal regime (sea) - choosing Ve river, Quang Ngai as an example. The simulation results were verificated on the series of real data measured continuously for 48 hours, which gave good and very good results in the cross section of MC0, where $\mathrm{R}^{2}$ reached 0,825 , Nash reached 0,798, PBIAS reached 6,919, RSR reached 0,524. The MIKE 3 model after the validation phase is used to simulate the dependence of the salinity level and range depending on tidal conditions and currents. The results show that the salt penetration rate is highly dependent on both the tidal regime and the current. The 3D model makes it possible to clarify the difference in salinity transfer between the dry season and the rainy season in the Ve estuary, especially the salinity transfer mechanism at the estuary.
\end{abstract}

Keywords: Rainfall-Runnoff; SWAT; NAM; MIKE; Ve River. 